Bioconjug Chem. 2019 October 16; 30(10): 2594-2603. doi:10.1021/acs.bioconjchem.9b00526.

\title{
Multivalent Cluster Nanomolecules for Inhibiting Protein-Protein Interactions
}

\author{
Elaine A. Qian ${ }^{1,2,3}$, Yanxiao Han ${ }^{4}$, Marco S. Messina ${ }^{1,3}$, Heather D. Maynard ${ }^{1,2,3}$, Petr \\ Král ${ }^{4,5,6}$, Alexander M. Spokoyny ${ }^{1,3,}{ }^{*}$ \\ ${ }^{1}$ Department of Chemistry and Biochemistry, University of California, Los Angeles, California \\ 90095, United States \\ ${ }^{2}$ Department of Bioengineering, University of California, Los Angeles, California 90095, United \\ States \\ ${ }^{3}$ California NanoSystems Institute, University of California, Los Angeles, California 90095, United \\ States \\ ${ }^{4}$ Department of Chemistry, University of Illinois at Chicago, Chicago, Illinois 60607, United States \\ ${ }^{5}$ Department of Physics, University of Illinois at Chicago, Chicago, Illinois 60607, United States \\ ${ }^{6}$ Department of Biopharmaceutical Sciences, University of Illinois at Chicago, Chicago, Illinois \\ 60607, United States
}

\begin{abstract}
Multivalent protein-protein interactions serve central roles in many essential biological processes, ranging from cell signaling and adhesion to pathogen recognition. Uncovering the rules that govern these intricate interactions is important not only to basic biology and chemistry, but also to the applied sciences where researchers are interested in developing molecules to promote or inhibit these interactions. Here we report the synthesis and application of atomically precise inorganic cluster nanomolecules consisting of an inorganic core and a covalently linked densely-packed layer of saccharides. These hybrid agents are stable under biologically relevant conditions and exhibit multivalent binding capabilities, which enable us to study the complex interactions between glycosylated structures and a dendritic cell lectin receptor. Importantly, we find that subtle changes in the molecular structure lead to significant differences in the nanomolecule's protein-binding properties. Furthermore, we demonstrate an example of using these hybrid nanomolecules to effectively inhibit protein-protein interactions in a human cell line. Ultimately,
\end{abstract}

\footnotetext{
*Corresponding Author: spokoyny@ chem.ucla.edu.

Safety Statement

No unexpected or unusually high safety hazards were encountered.

Supporting Information

The Supporting Information is available free of charge on the ACS Publications website. All methods, synthetic procedures, characterization data, supplementary data, and MD simulation movies.

Conflict of Interests: UCLA has patents on several compounds reported in this work from which A.M.S. and current/former coworkers receive royalty payments. Compounds 1 (Catalog \#902209) and $\mathbf{2}$ (Catalog \#901272) are commercially available through MilliporeSigma catalog.
} 
this work reveals an intricate interplay between the structural design of multivalent agents and their biological activities toward protein surfaces.

\section{Graphical Abstract}

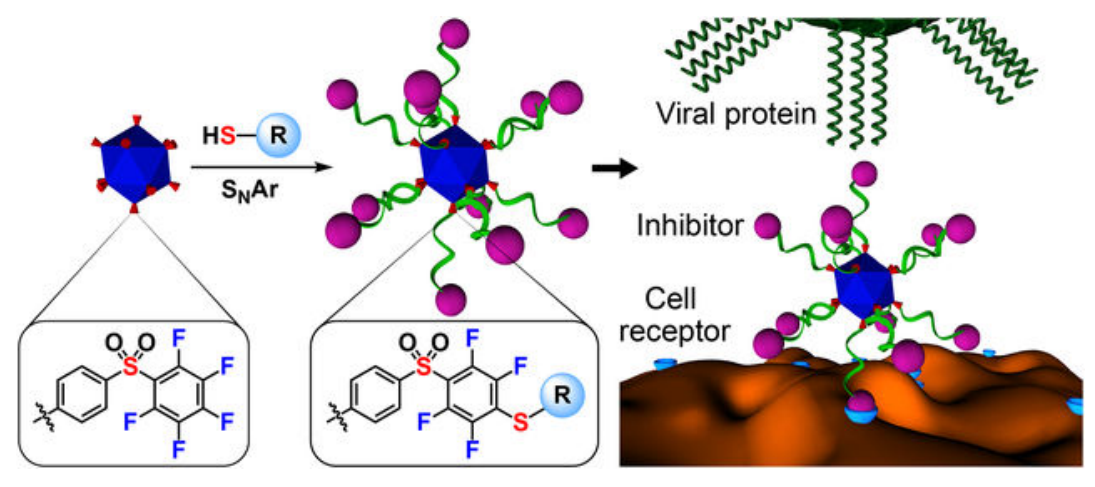

Multivalency is a prevalent phenomenon that facilitates many important biological processes in nature. ${ }^{1}$ Some of the most fascinating examples are found in our own immune system, where multivalency plays a crucial role in modulating several central functions of the immune cells, including cell signaling, cell-cell interaction, and pathogen recognition. ${ }^{2-5} \mathrm{~A}$ notable example of these intricate interactions takes place between glycoproteins and lectins, whose specificity and affinity toward each other are greatly amplified through multivalency. The important role multivalency plays in nature has fascinated both biologists and chemists alike, who are mutually interested in understanding the fundamental mechanisms behind these supramolecular recognition events as well as developing abiotic tools that are inspired by natural phenomena. ${ }^{5-9}$

An important biological target for studying multivalency is a C-type lectin receptor called dendritic cell-specific intercellular adhesion molecule-3-grabbing nonintegrin (DC-SIGN). ${ }^{10}$ Predominately expressed on the surface of dendritic cells, it organizes into a homotetrameric structure that is critical for the multivalent recognition of pathogens. ${ }^{11,12}$ In particular, DCSIGN is able to bind specific high-mannose glycoproteins and glycolipids on pathogens with high avidity, which activates a sequence of downstream responses including pathogen uptake and degradation as well as subsequent antigen processing and presentation. ${ }^{13}$ However, various pathogens such as HIV-1 have been observed to escape the intracellular degradation pathway following DC-SIGN-facilitated uptake. ${ }^{14}$ While the mechanism behind this unusual behavior is not well understood, it is clear that DC-SIGN plays an instrumental role in transmitting HIV-1 to the T cells and enhancing the infection in its early stages. ${ }^{14-16}$ Therefore, there is significant interest in 1) uncovering the rules that govern the multivalent interactions between DC-SIGN and high-mannose glycoconjugates and 2) inhibiting the DC-SIGN-dependent attachment and uptake of certain pathogens. One of the most promising approaches that can potentially tackle both challenges is centered around building molecules that can mimic the dense multivalent display of carbohydrates on the pathogen surface. ${ }^{8,9,17-19}$ 
Previously, several promising classes of glycomimetic ligands for DC-SIGN have been designed and synthesized, which include but are not limited to small molecules, ${ }^{20,21}$ peptides, ${ }^{22,23}$ linear and dendritic polymers, ${ }^{24-30}$ fullerenes, ${ }^{31,32}$ supramolecular assemblies, 33-35 and hybrid nanoparticles. ${ }^{36-38}$ These constructs are capable of engaging DC-SIGN with high avidities ( $K_{\mathrm{D}}$ spanning $\mathrm{nM}-\mu \mathrm{M}$ ), which allowed several of these systems to inhibit viral entry and infection. In particular, rigid three-dimensional (3D) architectures such as thiol-capped gold nanoparticles (AuNPs) are attractive glycomimetic platforms due to the ease of generating tunable and well-defined multivalent agents. Nevertheless, due to the weak bonding interactions between gold and thiol-based ligands, the surface morphology of these systems is poorly defined and highly dynamic, especially under biologically relevant conditions. ${ }^{39-42}$ This ultimately hinders researchers' ability to understand the precise structure-activity relationships of these systems with respect to biomolecular recognition and binding events.

Here we report the synthesis of a family of atomically precise glycosylated cluster nanomolecules featuring robust inorganic cluster scaffolds as nanoparticle core templates. Specifically, we developed conditions that allow the rapid functionalization of perfluoroarylbased moieties covalently grafted onto a rigid dodecaborate core via "click"-like nucleophilic aromatic substitution $\left(\mathrm{S}_{\mathrm{N}} \mathrm{Ar}\right)$ chemistry, thus leading to fully covalent nanomolecules with a densely packed layer of saccharides. ${ }^{43,44}$ This chemistry mimics the operational simplicity with which thiol-capped AuNPs are synthesized, yet produces welldefined assemblies that are stable under biologically relevant conditions. ${ }^{44}$ Importantly, direct binding studies between these hybrid assemblies and DC-SIGN reveal the multivalency-enhanced avidity in addition to the carbohydrate specificity of the lectin and the structural requirements for the multivalent ligands. Furthermore, competitive binding data suggest the mannose-coated nanomolecules can inhibit the protein-protein interactions between DC-SIGN and an HIV-1 envelope glycoprotein, gp120. Moreover, we found that the nanomolecules exhibit no apparent toxicity to a human lymphoblast-like cell line at $0.5-$ $50 \mu \mathrm{M}$ concentrations. This allowed us to perform cellular experiments, which revealed that the mannose-functionalized clusters are capable of preventing the cell uptake of gp120 by blocking cell-surface DC-SIGN. Therefore, we demonstrate that easily accessible, precisely engineered hybrid cluster-based nanomolecules can be utilized to not only study the rules governing multivalent recognition, but also inhibit protein-protein interactions in cells.

\section{Results and Discussion}

Given our success in installing a wide scope of thiols onto the perfluoroaryl-

perfunctionalized clusters using $\mathrm{S}_{\mathrm{N}} \mathrm{Ar}$ chemistry, ${ }^{44}$ we hypothesized that this strategy could be applied to generate a library of atomically precise nanomolecules featuring a variety of saccharides densely packed on the rigid 3D surface. Using the perfluoroarylperfunctionalized cluster 2 (Figure 1a) and 1-thio- $\beta$-D-mannose tetraacetate, ${ }^{44-47}$ we performed $\mathrm{S}_{\mathrm{N}} \mathrm{Ar}$ reactions in the presence of base in dimethylformamide (DMF), stirring under a $\mathrm{N}_{2}$ atmosphere. These test conjugation reactions revealed significant conversions, as determined by ${ }^{19} \mathrm{~F}$ NMR spectroscopy. Following efficient optimization facilitated by in situ ${ }^{19} \mathrm{~F}$ NMR spectroscopy, we found that employing an excess of the thiol and potassium phosphate $\left(\mathrm{K}_{3} \mathrm{PO}_{4}\right)$ allowed the nearly quantitative ( $\left.299 \%\right)$ substitution of 2 with the 
substrate within 48 hours. The product was briefly treated with sodium methoxide $(\mathrm{NaOMe})$ to remove all the acetyl groups, then purified by a desalting centrifugal filter to yield the mannose-coated nanomolecule 2a (Table 1, entry 1) in $80 \%$ isolated yield (see the Supporting Information for experimental details). The purified 2a was subsequently subjected to characterization via ${ }^{1} \mathrm{H},{ }^{11} \mathrm{~B}$, and ${ }^{19} \mathrm{~F}$ NMR spectroscopy and electrospray ionization-high resolution mass spectrometry (ESI-HRMS), which support the proposed structure and composition (see the Supporting Information for characterization data). Furthermore, we found that a similar strategy could be used to perfunctionalize 2 with 1thio- $\beta$-D-galactose tetraacetate within 48 hours, ${ }^{47,48}$ giving rise to the purified nanomolecule $\mathbf{2 b}$ (Table 1, entry 2), after isolation in $84 \%$ yield (see the Supporting Information for experimental details and characterization data). Additionally, we prepared previously reported glucose- and poly(ethylene glycol) (PEG)-coated structures $\mathbf{2 c}$ and $\mathbf{2 d}$ (Table 1, entries 3 and 4), ${ }^{44}$ and notably the isolated yield for $\mathbf{2} \mathbf{c}$ was significantly improved (17\% to $65 \%$ ) through the new purification strategy (see the Supporting Information for experimental details). Overall, these results demonstrate that perfluoroaryl-thiol $\mathrm{S}_{\mathrm{N}} \mathrm{Ar}$ chemistry can be utilized to assemble a panel of well-defined, multivalent hybrid nanomolecules functionalized with various saccharides including mannose, galactose, and glucose. Moreover, both the glycosylated and PEGylated nanomolecules can be easily purified using desalting centrifugal filters, which streamlines access to the pure materials. Ultimately, these nanomolecules provide us with the ability to evaluate the biological activities of multivalent assemblies as a function of the molecular structure precisely displayed in 3D space.

With the successful synthesis of glycosylated nanomolecules $\mathbf{2 a - c}$, we sought to build a new generation of multivalent architectures that share the precision and rigidity of the firstgeneration assemblies, but feature a rationally designed linker that will modularly extend the cluster scaffold. We envisioned that the new class of larger-sized glycosylated nanomolecules featuring a distinct multivalent display of saccharides, when studied alongside 2a-c, will allow us to further investigate the complex relationship between molecular structure and activity in the multivalent constructs. Keeping the downstream biological applications in mind, we set out to find a rigid linker that could ideally lead to water-soluble glycosylated nanomolecules. After testing multiple linker designs, we found a sulfone-bridged biphenyl derivative (Figure 1a) to be the most suitable candidate. The rationale behind choosing this linker was two-fold - not only could the polar sulfone group promote the overall water solubility of the nanomolecule (our attempt to use a biphenyl motif resulted in a poorly water-soluble glycosylated cluster), but also a similar molecule, decafluoro-biphenylsulfone, was recently found to exhibit remarkably fast $\mathrm{S}_{\mathrm{N}} \mathrm{Ar}$ reactivity toward cysteine residues on peptides under aqueous conditions. ${ }^{49}$ Therefore, we hypothesized that perfunctionalization of $\mathbf{1}$ (Figure 1a) with the sulfone-bridged linker could enhance the $S_{N} A r$ reaction kinetics and impart aqueous compatibility to the cluster conjugation, resulting in a water-soluble glycosylated species. The target benzyl bromide linker containing a terminal $\mathrm{SO}_{2} \mathrm{C}_{6} \mathrm{~F}_{5}$ functional group was synthesized in three steps (see the Supporting Information for experimental details and characterization data). Using a microwave-assisted synthesis method, ${ }^{50}$ we observed nearly quantitative conversion of $\mathbf{1}$ to the perfunctionalized cluster within 30 minutes, based on ${ }^{11}$ B NMR spectroscopy and ESIHRMS. The cluster species was isolated from the residual organic-based starting materials 
via silica gel chromatography in $94 \%$ yield. After subjecting the compound to a sodium ion exchange column, 3 (Figure 1a) was isolated as a light salmon-colored solid (see the Supporting Information for experimental details). ${ }^{1} \mathrm{H},{ }^{11} \mathrm{~B}$, and ${ }^{19} \mathrm{~F}$ NMR spectroscopy (Figure 1c) and ESI-HRMS results of $\mathbf{3}$ are consistent with the proposed structure and composition of the dodeca-functionalized $\mathrm{B}_{12}$-based cluster (see the Supporting Information for characterization data).

To test whether cluster $\mathbf{3}$ exhibits enhanced $\mathrm{S}_{\mathrm{N}} \mathrm{Ar}$ reactivity toward thiols, we exposed $\mathbf{3}$ dissolved in DMF to a stoichiometric amount of an unprotected thiolated saccharide, 1-thio$\beta$-D-glucose sodium salt, and observed by ${ }^{19} \mathrm{~F}$ NMR spectroscopy a nearly quantitative ( $299 \%$ ) conversion to 3c (Table 1, entry 7) within 20 minutes (Figure 1b, c). The purified water-soluble $\mathbf{3 c}$ was obtained via a desalting centrifugal filter, and was subjected to analysis via ${ }^{1} \mathrm{H},{ }^{11} \mathrm{~B}$, and ${ }^{19} \mathrm{~F}$ NMR spectroscopy and ESI-HRMS, which support the proposed structure and composition (see the Supporting Information for experimental details and characterization data). Notably, due to the rapid kinetics, this reaction did not require a $\mathrm{N}_{2}$ atmosphere in order to proceed to completion, therefore all subsequent conjugation reactions of $\mathbf{3}$ were performed under ambient conditions. Parallel experiments monitoring the $\mathrm{S}_{\mathrm{N}} \mathrm{Ar}$ reaction conversion over time of $\mathbf{2}$ and $\mathbf{3}$ by ${ }^{19} \mathrm{~F}$ NMR spectroscopy revealed the significantly improved conversion rates of $\mathbf{3}$ over $\mathbf{2}$ (Figure 1b), which is consistent with our hypothesis. We then proceeded to test whether $\mathbf{3}$ tolerates water in the conjugation reaction by subjecting 3 to a stoichiometric amount of 1 -thio- $\beta$-D-glucose sodium salt in 1:1 DMF:water and 1:1 acetonitrile (MeCN):water mixtures, and in both cases observed nearly quantitative ( $299 \%$ ) conversion to $3 \mathbf{c}$ within 15 minutes (Figure 1c) (see the Supporting Information for experimental details). These remarkably fast reaction kinetics in mixed aqueous/organic media are consistent with the observations by Kalhor-Monfared et al. and furthermore may be facilitated by the enhanced solubility of 1-thio- $\beta$-D-glucose sodium salt in water. ${ }^{49}$ Overall, these studies demonstrate that by employing rational linker design, the $\mathrm{S}_{\mathrm{N}} \mathrm{Ar}$ reaction characteristics including kinetics and aqueous compatibility can be dramatically enhanced, allowing for the rapid assembly of atomically precise, densely glycosylated nanomolecules.

Based on the successful glycosylation of $\mathbf{2}$ to yield functionalized nanomolecules $\mathbf{2 a - c}$, we hypothesized that $\mathbf{3}$ could likewise be glycosylated by mannose and galactose in addition to glucose (vide supra). Treatment of $\mathbf{3}$ with the sodium salts of 1-thio- $\boldsymbol{a}$-D-mannose and 1thio- $\beta$-D-galactose in 1:1 DMF:water mixtures resulted in nearly quantitative ( $₫ 99 \%$ ) conversions within 15 minutes to $\mathbf{3 a}$ and $\mathbf{3 b}$ (Table 1 , entries 5 and 6), respectively. Following purification, $\mathbf{3 a}$ and $\mathbf{3 b}$ were subjected to characterization via ${ }^{1} \mathrm{H},{ }^{11} \mathrm{~B}$, and ${ }^{19} \mathrm{~F}$ NMR spectroscopy and ESI-HRMS, which support the proposed structures and compositions (see the Supporting Information for experimental details and characterization data). Furthermore, we were able to fully PEGylate $\mathbf{3}$ within 90 minutes, giving rise to purified 3d (Table 1, entry 8) after isolation in 84\% yield (see the Supporting Information for experimental details and characterization data). These experiments demonstrate that cluster $\mathbf{3}$ can rapidly lead to a library of multivalent hybrid entities featuring diverse functional groups, which allows us to study how the specific surface chemistry affects the protein-binding properties. Ultimately, the family of precisely engineered multivalent 
nanomolecules ( $\mathbf{2} \mathbf{a}-\mathbf{3}$ and $\mathbf{3 a}-\mathbf{d}$, vide supra) creates a framework which can potentially enable us to study the fundamental rules that govern multivalent biological recognition events.

Following the assembly and isolation of the glycosylated and PEGylated clusters, we proceeded to uncover the binding characteristics of the various nanomolecules toward an important dendritic cell receptor, DC-SIGN. Among the existing techniques that can experimentally elucidate the binding affinities between complex molecules and biomolecular targets, the surface plasmon resonance (SPR) technology represents a "gold standard" used by researchers in both academic and biotechnology communities. 51,52 Given the ability of the SPR technology to perform real-time, label-free detection of biomolecular interactions with high sensitivity, ${ }^{52}$ we decided to use it for studying the binding interactions between the multivalent cluster nanomolecules and DC-SIGN. In the first set of SPR-based direct binding experiments, the tetrameric DC-SIGN extracellular domain (ECD) was immobilized on a commercial sensor chip via standard amide coupling, and the mannose-functionalized nanomolecules $\mathbf{2 a}$ and $\mathbf{3 a}$ were injected over the protein surface for real-time visualization of their respective binding interactions with DC-SIGN (see the Supporting Information for experimental details). The resulting sensorgrams (Figure 2a, d) reflect changes in the refractive index as molecules interact with the lectin surface, and reveal the dose-dependent binding response of $\mathbf{2 a}$ and $\mathbf{3 a}$, respectively, toward DC-SIGN. By fitting the Langmuir 1:1 binding model to the binding curves of the mannose-coated clusters, we estimated $K_{\mathrm{D}}$ values of $0.11 \mu \mathrm{M}$ for $\mathbf{2 a}$ and $5.0 \mu \mathrm{M}$ for 3a. Compared to D-mannose (low mM affinity), ${ }^{11}$ these multivalent systems exhibit avidities three to four orders of magnitude higher for DC-SIGN through the cluster glycoside effect. ${ }^{3}$ To further understand the dynamics of the multivalent interactions, we performed computational studies using a tetrameric model derived from an $\mathrm{X}$-ray structure of DC-SIGN (see the Supporting Information for experimental details). ${ }^{12,53}$ Molecular dynamics (MD) simulations of the interactions between the DC-SIGN model and 2a/3a over 40 ns were conducted, and snapshots were taken at the end of both simulations (Figure 2b-c/e-f, respectively; see the Supporting Information for experimental details and movies). The MD movies and snapshots suggest that consistent with previous reports using monosaccharides and oligosaccharides, ${ }^{11,12}$ the equatorial 3-OH and 4-OH groups on the cluster-linked mannose residues engage in $\mathrm{Ca}^{2+}$-mediated binding in the carbohydrate recognition sites. Furthermore, 2a was observed to stay longer than 3a near the binding site of the protein model (Figure S16), which agrees with the lower $K_{\mathrm{D}}$ value of $2 \mathbf{a}$ determined from the SPR experiments. A possible explanation for the observed difference in avidity is the flexibility of the linker - while the extended linker in 3a is still rigid, it allows more flexibility compared to the benzylic linker in 2a. Although a more flexible linker can relax the requirements for the precise positioning of ligands on a multivalent scaffold, it can also lower the overall affinity for a target protein. ${ }^{5}$

After analyzing the binding interactions of mannose-coated cluster nanomolecules toward DC-SIGN, we hypothesized that the clusters grafted with other saccharides would exhibit different protein-binding behaviors. Therefore, we conducted another set of SPR-based direct binding studies with the glucose-coated nanomolecules (2c and 3c) (Figures S1 and S2), which yielded $K_{\mathrm{D}}$ values of 0.18 and $30 \mu \mathrm{M}$, respectively. These similar but slightly 
higher $K_{\mathrm{D}}$ values compared to the mannose-coated analogs agree with results from previous reports using monosaccharides, ${ }^{11,54}$ which suggest the equatorial 3- and 4-OH groups on glucose allow a similar binding interaction with DC-SIGN. In contrast, the galactose-coated species ( $\mathbf{2} \mathbf{b}$ and $\mathbf{3 b}$ ) were unable to engage DC-SIGN with similar avidities (the estimated $K_{\mathrm{D}}$ values were 0.87 and $96 \mu \mathrm{M}$, respectively; Figures S3 and S4). This finding is also consistent with prior reports with monosaccharides and glycopolymers, ${ }^{11,24,54}$ since the axial 4-OH group on galactose prevents proper recognition by the carbohydrate-binding sites on DC-SIGN. In contrast, the controls - PEGylated clusters (2d and 3d) and D-mannose exhibit minimal to no binding to the protein surface when injected at the highest mass concentrations with respect to 2a and 3a (Figure 2a, d). Overall, these experiments reveal the dramatically enhanced binding avidities of the glycosylated cluster nanomolecules as a result of multivalency and highlight a potentially intricate relationship between the scaffold flexibility and the binding affinity. Nevertheless, in nature DC-SIGN is known to be a very flexible transmembrane receptor that can reposition its carbohydrate recognition domains to adapt to the ligands, ${ }^{55}$ and this dynamic behavior is not fully captured by the immobilized protein setup in the in vitro SPR and in silico MD experiments.

Therefore, we turned to SPR-based competitive binding assays in order to test 1) whether free (vs immobilized) DC-SIGN exhibits different binding characteristics to the cluster nanomolecules and 2) whether the mannose-coated species can inhibit the protein-protein interactions between DC-SIGN and a sub-nM binder, HIV-1 gp120. ${ }^{24,56}$ In these competition experiments, $100 \mathrm{nM}$ DC-SIGN and various concentrations of the nanomolecules were co-injected over the surface-immobilized gp120, and the binding response of each injection was compared to that of each preceding injection of DC-SIGN alone for an estimation of the \% inhibition of the DC-SIGN-gp120 interaction. As shown in Figure 3, 2a and 3a can both inhibit free DC-SIGN from attaching to gp120, with $\mathrm{IC}_{50}$ values of 2.0 and $5.2 \mu \mathrm{M}$, respectively. These values are over three orders of magnitude lower than the reported $\mathrm{IC}_{50}$ of monovalent D-mannose $(6-9 \mathrm{mM}),{ }^{54,57}$ indicating dramatically enhanced inhibition. Notably, compared with the $\mathrm{IC}_{50}$ values from a similar SPR-based competition assay using a multivalent third-generation dendrimer $(50 \mu \mathrm{M}, 32$ mannose residues), ${ }^{27}$ these values are an order of magnitude lower. These results suggest that rigid inorganic cluster-based nanomolecules featuring significantly fewer (12) saccharides can serve as more potent inhibitors of this protein-protein interaction. Furthermore, in agreement with the direct binding data, the galactose-coated $(\mathbf{2 b}, \mathbf{3 b})$ and PEGylated (2d, 3d) nanomolecules as well as D-mannose were less successful at inhibiting this interaction (Figures S5 and S6). Overall, these competition studies demonstrate for the first time the ability of multivalent glycosylated cluster nanomolecules to effectively compete against a sub-nM-binding viral glycoprotein for DC-SIGN. This suggests that a rigid cluster scaffold-based multivalent display of carbohydrates that mimics the natural highly glycosylated proteins on the surface of pathogens can be engineered to inhibit the interactions between a cell-based lectin receptor and a viral glycoprotein. Moreover, the similarity in $\mathrm{IC}_{50}$ values for $\mathbf{2 a}$ and $\mathbf{3 a}$ in contrast to their different $K_{\mathrm{D}}$ values could be due to a combination of the free (vs immobilized) DC-SIGN better adapting to the more flexible nanomolecule 3a and the greater receptor surface coverage by the larger nanomolecule 3a. 
To further investigate the ability of the mannose-functionalized cluster nanomolecules to inhibit the protein-protein interactions between DC-SIGN and gp120 in an experimental setup more reminiscent of natural systems, we moved to cell-based studies using a DCSIGN-expressing human lymphoblast-like cell line (Raji DC-SIGN+ cells) and HIV-1 gp120 (Figure 4a). ${ }^{58,59}$ First, in order to gain a better understanding of the biocompatibility of the cluster nanomolecules, we conducted an MTS-based cell proliferation assay (see the Supporting Information for experimental details), and observed no apparent cytotoxic effects of the mannose-coated (2a, 3a) and PEGylated (2d, 3d) clusters toward Raji DC-SIGN+ cells at $0.5-50 \mu \mathrm{M}$ concentrations (Figure $4 \mathrm{~b}$ ). This finding allowed the evaluation of the nanomolecules' potential biological function in inhibiting the attachment of gp120 to cellsurface DC-SIGN. Fluorescein isothiocyanate-labeled gp120 (gp120-FITC) undergoes significant uptake by Raji DC-SIGN+ cells (Figure 4c), as observed by a confocal laser scanning microscopy-based assay (see the Supporting Information for experimental details and Figures S7-S15). This internalization is DC-SIGN-dependent since no gp120-FITC uptake was observed in a Raji cell line not expressing DC-SIGN (Figure 4c). ${ }^{60,61}$ In order to test competitive inhibition, we introduced mixtures of gp120-FITC and mannose-coated clusters 2a/3a to Raji DC-SIGN+ cells, and observed reduced gp120-FITC uptake as a function of the cluster concentration (10 to $25 \mu \mathrm{M}$ ) (Figure 4c). Notably, at the same concentrations, 3a was more effective than $\mathbf{2 a}$ at preventing the binding and uptake of gp120-FITC. This result suggests that 3a can bind DC-SIGN in its natural transmembrane conformation better, which could be due to its higher flexibility and larger size. Furthermore, these cell-based studies capture important information about the dynamic receptor-mediated antigen internalization process, ${ }^{62}$ thus enabling us to assess both the nanomolecules' binding to DC-SIGN and the inhibition of antigen uptake. Consistent with the presented SPR-based direct and competitive binding data, the control molecules - PEGylated clusters ( $2 \mathbf{d}$ and $\mathbf{3 d}$ ) and D-mannose - were not able to bind to DC-SIGN and inhibit gp120 uptake at $25 \mu \mathrm{M}$ (Figure 4c). Overall, the biological studies in cells reveal that biocompatible mannosefunctionalized cluster nanomolecules are capable of competing against HIV-1 gp120 for cell-surface DC-SIGN and thereby preventing the receptor-mediated internalization of a viral envelope component.

\section{Conclusions}

We have demonstrated the rapid assembly of multivalent glycosylated inorganic cluster nanomolecules capable of inhibiting protein-protein interactions. Specifically, a dense layer of thiolated saccharides can be grafted on a rigid perfluoroaryl-perfunctionalized $\mathrm{B}_{12}$ cluster within 15 minutes in mixed aqueous/organic media using $\mathrm{S}_{\mathrm{N}} \mathrm{Ar}$ chemistry. The resulting fully covalent glycosylated assemblies can serve as multivalent binders with dramatically enhanced affinity compared to monovalent saccharides toward target lectins. We showed an example of using these hybrid agents for engendering ligand-specific, multivalent recognition with a biologically important dendritic cell receptor, DC-SIGN. Importantly, we demonstrated the ability of the cluster nanomolecules to inhibit protein-protein interactions between DC-SIGN and a sub-nM-binding HIV-1 envelope glycoprotein in a competitive binding study. We further found these clusters to be biocompatible in a human cell line and capable of preventing the internalization of gp120 by DC-SIGN-expressing cells. Notably, 
we uncovered an intricate interplay between the structural designs of multivalent binders and their biological activities. We strive to further elucidate the structure-activity relationship of well-defined multivalent agents through vertex-differentiated clusters ${ }^{63}$ and other types of molecular scaffolds. Ultimately, this work showcases a rare example of the application of tunable, stable inorganic cluster-based nanomolecules as valuable tools for studying the rules that govern multivalent interactions and disrupting protein-protein interactions. ${ }^{64-66}$

\section{Supplementary Material}

Refer to Web version on PubMed Central for supplementary material.

\section{Acknowledgments}

E.A.Q. thanks the NIH for the Predoctoral Training Fellowship through the UCLA Chemistry-Biology Interface Training Program under the National Research Service Award (T32GM008496) and the UCLA Graduate Division for the Dissertation Year Fellowship. M.S.M. is grateful to the National Science Foundation (NSF) for the Bridgeto-Doctorate (HRD-1400789) and the Predoctoral (DGE-0707424) Fellowships and UCLA for the Christopher S. Foote Fellowship. H.D.M. thanks the Dr. Myung Ki Hong Endowed Chair in Polymer Science. A.M.S. thanks the UCLA Department of Chemistry and Biochemistry for start-up funds, $3 \mathrm{M}$ for a Non-Tenured Faculty Award, the Alfred P. Sloan Foundation for a Fellowship in Chemistry, Research Corporation for Science Advancement (RCSA) for a Cottrell Scholar Award, and the National Institutes of Health (NIH) for a Maximizing Investigators Research Award (MIRA, R35GM124746). We are grateful for the assistance from Dr. Alex I. Wixtrom in optimizing the synthesis of 2. We thank UCLA Molecular Instrumentation Center for mass spectrometry (NIH 1S10OD016387-01) and NMR spectroscopy. We also thank the UCLA Biochemistry Instrumentation Facility for use of the SPR instrument. The following reagents were obtained through the NIH AIDS Reagent Program, Division of AIDS, NIAID, NIH: pcDNA3-DC-SIGN from Drs. S. Pöhlmann, F. Baribaud, F. Kirchhoff, and R.W. Doms, ${ }^{67}$ HIV-1 CM235 gp120 recombinant protein from NIAID, DAIDS, and both Raji and Raji DC-SIGN+ cells from Drs. Li Wu and Vineet N. KewalRamani. ${ }^{58}$

\section{References}

(1). Mammen M; Choi S-K; Whitesides GM Polyvalent interactions in biological systems: implications for design and use of multivalent ligands and inhibitors. Angew. Chem., Int. Ed 1998, 37, 2754-2794.

(2). Weis WI; Taylor ME; Drickamer K The C-type lectin superfamily in the immune system. Immunol. Rev 1998, 163, 19-34. [PubMed: 9700499]

(3). Lundquist JJ; Toone EJ The cluster glycoside effect. Chem. Rev 2002, 102, 555-578. [PubMed: 11841254]

(4). Wolfert MA; Boons GJ Adaptive immune activation: glycosylation does matter. Nat. Chem. Biol 2013, 9, 776-784. [PubMed: 24231619]

(5). Multivalency, 1st ed.; Huskens J, Prins LJ, Haag R, Ravoo BJ, Eds.; John Wiley \& Sons: Hoboken, NJ, 2018.

(6). Conn MM; Rebek J Self-assembling capsules. Chem. Rev 1997, 97, 1647-1668. [PubMed: 11851461]

(7). Müller C; Despras G; Lindhorst TK Organizing multivalency in carbohydrate recognition. Chem. Soc. Rev 2016, 45, 3275-3302. [PubMed: 27146554]

(8). Bernardi A; Jiménez-Barbero J; Casnati A; De Castro C; Darbre T; Fieschi F; Finne J; Funken H; Jaeger K-E; Lahmann M; et al. Multivalent glycoconjugates as anti-pathogenic agents. Chem. Soc. Rev 2013, 42, 4709-4727. [PubMed: 23254759]

(9). Bhatia S; Camacho LC; Haag R Pathogen inhibition by multivalent ligand architectures. J. Am. Chem. Soc 2016, 138, 8654-8666. [PubMed: 27341003]

(10). Geijtenbeek TBH; Torensma R; Van Vliet SJ; Van Duijnhoven GCF; Adema GJ; Van Kooyk Y; Figdor CG Identification of DC-SIGN, a novel dendritic cell-specific ICAM-3 receptor that supports primary immune responses. Cell 2000, 100, 575-585. [PubMed: 10721994] 
(11). Mitchell DA; Fadden AJ; Drickamer K A novel mechanism of carbohydrate recognition by the C-type lectins DC-SIGN and DC-SIGNR. Subunit organization and binding to multivalent ligands. J. Biol. Chem 2001, 276, 28939-28945. [PubMed: 11384997]

(12). Feinberg H; Mitchell DA; Drickamer K; Weis WI Structural basis for selective recognition of oligosaccharides by DC-SIGN and DC-SIGNR. Science 2001, 294, 2163-2166. [PubMed: 11739956]

(13). Švajger U; Anderluh M; Jeras M; Obermajer N C-type lectin DC-SIGN: an adhesion, signalling and antigen-uptake molecule that guides dendritic cells in immunity. Cell. Signal 2010, 22, 1397-1405. [PubMed: 20363321]

(14). van Kooyk Y; Geijtenbeek TBH DC-SIGN: escape mechanism for pathogens. Nat. Rev. Immunol 2003, 3, 697-709. [PubMed: 12949494]

(15). Geijtenbeek TBH; Kwon DS; Torensma R; Van Vliet SJ; Van Duijnhoven GCF; Middel J; Cornelissen ILMHA; Nottet HSLM; KewalRamani VN; Littman DR; et al. DC-SIGN, a dendritic cell-specific HIV-1-binding protein that enhances trans-infection of T cells. Cell 2000, 100, 587597. [PubMed: 10721995]

(16). Chung NPY; Breun SKJ; Bashirova A; Baumann JG; Martin TD; Karamchandani JM; Rausch JW; Le Grice SFJ; Wu L; Carrington M; et al. HIV-1 transmission by dendritic cell-specific ICAM-3-grabbing nonintegrin (DC-SIGN) is regulated by determinants in the carbohydrate recognition domain that are absent in liver/lymph node-sign (L-SIGN). J. Biol. Chem 2010, 285, 2100-2112. [PubMed: 19833723]

(17). Lepenies B; Lee J; Sonkaria S Targeting C-type lectin receptors with multivalent carbohydrate ligands. Adv. Drug Deliv. Rev 2013, 65, 1271-1281. [PubMed: 23727341]

(18). Kamiya N; Tominaga M; Sato S; Fujita M Saccharide-coated $\mathrm{M}_{12} \mathrm{~L}_{24}$ molecular spheres that form aggregates by multi-interaction with proteins. J. Am. Chem. Soc 2007, 129, 3816-3817. [PubMed: 17343384]

(19). Zhang Q; Savagatrup S; Kaplonek P; Seeberger PH; Swager TM Janus emulsions for the detection of bacteria. ACS Cent. Sci 2017, 3, 309-313. [PubMed: 28470048]

(20). Sattin S; Daghetti A; Thépaut M; Berzi A; Sánchez-Navarro M; Tabarani G; Rojo J; Fieschi F; Clerici M; Bernardi A Inhibition of DC-SIGN-mediated HIV infection by a linear trimannoside mimic in a tetravalent presentation. ACS Chem. Biol 2010, 5, 301-312. [PubMed: 20085340]

(21). Borrok MJ; Kiessling LL Non-carbohydrate inhibitors of the lectin DC-SIGN. J. Am. Chem. Soc 2007, 129, 12780-12785. [PubMed: 17902657]

(22). Frison N; Taylor ME; Soilleux E; Bousser M-T; Mayer R; Monsigny M; Drickamer K; Roche AC Oligolysine-based oligosaccharide clusters. J. Biol. Chem 2003, 278, 23922-23929. [PubMed: 12695508]

(23). Ng S; Bennett NJ; Schulze J; Gao N; Rademacher C; Derda R Genetically-encoded fragmentbased discovery of glycopeptide ligands for DC-SIGN. Bioorganic Med. Chem 2018, 26, 53685377.

(24). Becer CR; Gibson MI; Geng J; Ilyas R; Wallis R; Mitchell DA; Haddleton DM High-affinity glycopolymer binding to human DC-SIGN and disruption of DC-SIGN interactions with HIV envelope glycoprotein. J. Am. Chem. Soc 2010, 132, 15130-15132. [PubMed: 20932025]

(25). Turnbull WB; Stoddart JF Design and synthesis of glycodendrimers. Rev. Mol. Biotechnol 2002, 90, 231-255.

(26). Lasala F; Arce E; Otero JR; Rojo J; Delgado R Mannosyl glycodendritic structure inhibits DCSIGN-mediated Ebola virus infection in cis and in trans. Antimicrob. Agents Chemother 2003, 47, 3970-3972. [PubMed: 14638512]

(27). Tabarani G; Reina JJ; Ebel C; Vivès C; Lortat-Jacob H; Rojo J; Fieschi F Mannose hyperbranched dendritic polymers interact with clustered organization of DC-SIGN and inhibit gp120 binding. FEBS Lett. 2006, 580, 2402-2408. [PubMed: 16616922]

(28). Luczkowiak J; Sattin S; Sutkevičiute I; Reina JJ; Sánchez-Navarro M; Thépaut M; Martínez-Prats L; Daghetti A; Fieschi F; Delgado R; et al. Pseudosaccharide functionalized dendrimers as potent inhibitors of DC-SIGN dependent Ebola pseudotyped viral infection. Bioconjugate Chem. 2011, 22, 1354-1365. 
(29). Garcia-Vallejo JJ; Koning N; Ambrosini M; Kalay H; Vuist I; Sarrami-Forooshani R; Geijtenbeek TBH; van Kooyk Y Glycodendrimers prevent HIV transmission via DC-SIGN on dendritic cells. Int. Immunol 2013, 25, 221-233. [PubMed: 23291968]

(30). Ordanini S; Varga N; Porkolab V; Thépaut M; Belvisi L; Bertaglia A; Palmioli A; Berzi A; Trabattoni D; Clerici M; et al. Designing nanomolar antagonists of DC-SIGN-mediated HIV infection: ligand presentation using molecular rods. Chem. Commun 2015, 51, 3816-3819.

(31). Luczkowiak J; Muñoz A; Sánchez-Navarro MA; Ribeiro-viana R; Ginieis A; Illescas BM; Martín N; Delgado R; Rojo J; Mart N; et al. Glycofullerenes inhibit viral infection. Biomacromolecules 2013, 14, 431-437. [PubMed: 23281578]

(32). Muñoz A; Sigwalt D; Illescas BM; Luczkowiak J; Rodríguez-Pérez L; Nierengarten I; Holler M; Remy JS; Buffet K; Vincent SP; et al. Synthesis of giant globular multivalent glycofullerenes as potent inhibitors in a model of Ebola virus infection. Nat. Chem 2016, 8, 50-57. [PubMed: 27055288]

(33). Delbianco M; Bharate P; Varela-Aramburu S; Seeberger PH Carbohydrates in supramolecular chemistry. Chem. Rev 2016, 116, 1693-1752. [PubMed: 26702928]

(34). Zhang Q; Su L; Collins J; Chen G; Wallis R; Mitchell DA; Haddleton DM; Becer CR Dendritic cell lectin-targeting sentinel-like unimolecular glycoconjugates to release an anti-HIV drug. J. Am. Chem. Soc 2014, 136, 4325-4332. [PubMed: 24568546]

(35). Morbioli I; Porkolab V; Magini A; Casnati A; Fieschi F; Sansone F Mannosylcalix[n]arenes as multivalent ligands for DC-SIGN. Carbohydr. Res 2017, 453-454, 36-43.

(36). Adak AK; Lin HJ; Lin CC Multivalent glycosylated nanoparticles for studying carbohydrateprotein interactions. Org. Biomol. Chem 2014, 12, 5563-5573. [PubMed: 24961902]

(37). Martínez-Ávila O; Hijazi K; Marradi M; Clavel C; Campion C; Kelly C; Penadés S Gold mannoglyconanoparticles: multivalent systems to block HIV-1 gp120 binding to the lectin DC-SIGN. Chem. - Eur. J 2009, 15, 9874-9888. [PubMed: 19681073]

(38). Ribeiro-Viana R; Sánchez-Navarro M; Luczkowiak J; Koeppe JR; Delgado R; Rojo J; Davis BG Virus-like glycodendrinanoparticles displaying quasi-equivalent nested polyvalency upon glycoprotein platforms potently block viral infection. Nat. Commun 2012, 3, 1303. [PubMed: 23250433]

(39). Hostetler MJ; Templeton AC; Murray RW Dynamics of place-exchange reactions on monolayerprotected gold cluster molecules. Langmuir 1999, 15, 3782-3789.

(40). Daniel M; Astruc D Gold nanoparticles: assembly, supramolecular chemistry, quantum-sizerelated properties, and applications toward biology, catalysis, and nanotechnology. Chem. Rev 2004, 104, 293-346. [PubMed: 14719978]

(41). Love JC; Estroff LA; Kriebel JK; Nuzzo RG; Whitesides GM Self-assembled monolayers of thiolates on metals as a form of nanotechnology. Chem. Rev 2005, 105, 1103-1170. [PubMed: 15826011]

(42). MacLeod MJ; Johnson JA PEGylated N-heterocyclic carbene anchors designed to stabilize gold nanoparticles in biologically relevant media. J. Am. Chem. Soc 2015, 137, 7974-7977. [PubMed: 26081724]

(43). Remzi Becer C; Hoogenboom R; Schubert US Click chemistry beyond metal-catalyzed cycloaddition. Angew. Chem., Int. Ed 2009, 48, 4900-4908.

(44). Qian EA; Wixtrom AI; Axtell JC; Saebi A; Jung D; Rehak P; Han Y; Moully EH; Mosallaei D; Chow $\mathrm{S}$; et al. Atomically precise organomimetic cluster nanomolecules assembled via perfluoroaryl-thiol $\mathrm{S}_{\mathrm{N}}$ Ar chemistry. Nat. Chem 2017, 9, 333-340. [PubMed: 28485398]

(45). Messina MS; Axtell JC; Wang Y; Chong P; Wixtrom AI; Kirlikovali KO; Upton BM; Hunter BM; Shafaat OS; Khan SI; et al. Visible-light-induced olefin activation using 3D aromatic boronrich cluster photooxidants. J. Am. Chem. Soc 2016, 138, 6952-6955. [PubMed: 27186856]

(46). Floyd N; Vijayakrishnan B; Koeppe JR; Davis BG Thiyl glycosylation of olefinic proteins: Slinked glycoconjugate synthesis. Angew. Chem., Int. Ed 2009, 48, 7798-7802.

(47). Pelegri-O'Day EM; Paluck SJ; Maynard HD Substituted polyesters by thiol-ene modification: rapid diversification for therapeutic protein stabilization. J. Am. Chem. Soc 2017, 139, 11451154. [PubMed: 28079370] 
(48). Zhu SJ; Ying HZ; Wu Y; Qiu N; Liu T; Yang B; Dong XW; Hu YZ Design, synthesis and biological evaluation of novel podophyllotoxin derivatives bearing $4 \beta$-disulfide/trisulfide bond as cytotoxic agents. RSC Adv. 2015, 5, 103172-103183.

(49). Kalhor-Monfared S; Jafari MR; Patterson JT; Kitov PI; Dwyer JJ; Nuss JM; Derda R Rapid biocompatible macrocyclization of peptides with decafluoro-diphenylsulfone. Chem. Sci 2016, 7, 3785-3790. [PubMed: 30155020]

(50). Wixtrom AI; Shao Y; Jung D; Machan CW; Kevork SN; Qian EA; Axtell JC; Khan SI; Kubiak $\mathrm{CP}$; Spokoyny AM Rapid synthesis of redox-active dodecaborane $\mathrm{B}_{12}(\mathrm{OR})_{12}$ clusters under ambient conditions. Inorg. Chem. Front 2016, 3, 711-717. [PubMed: 27885335]

(51). Hill RT Plasmonic biosensors. Wiley Interdiscip. Rev. Nanomedicine Nanobiotechnology 2015, 7, 152-168. [PubMed: 25377594]

(52). Olaru A; Bala C; Jaffrezic-Renault N; Aboul-Enein HY Surface plasmon resonance (SPR) biosensors in pharmaceutical analysis. Crit. Rev. Anal. Chem 2015, 45, 97-105. [PubMed: 25558771]

(53). Tabarani G; Thépaut M; Stroebel D; Ebei C; Vivès C; Vachette P; Durand D; Fieschi F; Thepaut $\mathrm{M}$; Stroebel D; et al. DC-SIGN neck domain is a $\mathrm{pH}$-sensor controlling oligomerization. SAXS and hydrodynamic studies of extracellular domain. J. Biol. Chem 2009, 284, 21229-21240. [PubMed: 19502234]

(54). Su SV; Hong P; Baik S; Negrete OA; Gurney KB; Lee B DC-SIGN binds to HIV-1 glycoprotein 120 in a distinct but overlapping fashion compared with ICAM-2 and ICAM-3. J. Biol. Chem 2004, 279, 19122-19132. [PubMed: 14970226]

(55). Menon S; Rosenberg K; Graham SA; Ward EM; Taylor ME; Drickamer K; Leckband DE Binding-site geometry and flexibility in DC-SIGN demonstrated with surface force measurements. Proc. Natl. Acad. Sci 2009, 106, 11524-11529. [PubMed: 19553201]

(56). Zhang Q; Collins J; Anastasaki A; Wallis R; Mitchell DA; Becer CR; Haddleton DM Sequencecontrolled multi-block glycopolymers to inhibit DC-SIGN-gp120 binding. Angew. Chem., Int. Ed 2013, 52, 4435-4439.

(57). Wang S-K; Liang P-H; Astronomo RD; Hsu T-L; Hsieh S-L; Burton DR; Wong C-H Targeting the carbohydrates on HIV-1: interaction of oligomannose dendrons with human monoclonal antibody 2G12 and DC-SIGN. Proc. Natl. Acad. Sci 2008, 105, 3690-3695. [PubMed: 18310320]

(58). Wu L; Martin TD; Carrington M; KewalRamani VN Raji B cells, misidentified as THP-1 cells, stimulate DC-SIGN-mediated HIV transmission. Virology 2004, 318, 17-23. [PubMed: 14972530]

(59). Liu J; Bartesaghi A; Borgnia MJ; Sapiro G; Subramaniam S Molecular architecture of native HIV-1 gp120 trimers. Nature 2008, 455, 109-113. [PubMed: 18668044]

(60). Mangold SL; Prost LR; Kiessling LL Quinoxalinone inhibitors of the lectin DC-SIGN. Chem. Sci 2012, 3, 772-777. [PubMed: 22639721]

(61). Arnáiz B; Martínez-Ávila O; Falcon-Perez JM; Penadés S Cellular uptake of gold nanoparticles bearing HIV gp120 oligomannosides. Bioconjugate Chem. 2012, 23, 814-825.

(62). Boulant S; Stanifer M; Lozach PY Dynamics of virus-receptor interactions in virus binding, signaling, and endocytosis. Viruses 2015, 7, 2794-2815. [PubMed: 26043381]

(63). Wixtrom AI; Parvez ZA; Savage MD; Qian EA; Jung D; Khan SI; Rheingold AL; Spokoyny AM Tuning the electrochemical potential of perfunctionalized dodecaborate clusters through vertex differentiation. Chem. Commun 2018, 54, 5867-5870.

(64). Řezáčová P; Pokorná J; Brynda J; Kožǐšek M; Cígler P; Lepšík M; Fanfrlík J; Řezáč J; Šašková KG; Sieglová I; et al. Design of HIV protease inhibitors based on inorganic polyhedral metallacarboranes. J. Med. Chem 2009, 52, 7132-7141. [PubMed: 19874035]

(65). Lo Conte M; Staderini S; Chambery A; Berthet N; Dumy P; Renaudet O; Marra A; Dondoni A Glycoside and peptide clustering around the octasilsesquioxane scaffold via photoinduced freeradical thiol-ene coupling. The observation of a striking glycoside cluster effect. Org. Biomol. Chem 2012, 10, 3269-3277. [PubMed: 22411077] 
(66). Levine DJ; Stöhr J; Falese LE; Ollesch J; Wille H; Prusiner SB; Long JR Mechanism of scrapie prion precipitation with phosphotungstate anions. ACS Chem. Biol 2015, 10, 1269-1277. [PubMed: 25695325]

(67). Pöhlmann S; Baribaud F; Lee B; Leslie GJ; Sanchez MD; Hiebenthal-Millow K; Münch J; Kirchhoff F; Doms RW DC-SIGN interactions with human immunodeficiency virus type 1 and 2 and simian immunodeficiency virus. J. Virol 2001, 75, 4664-4672. [PubMed: 11312337] 

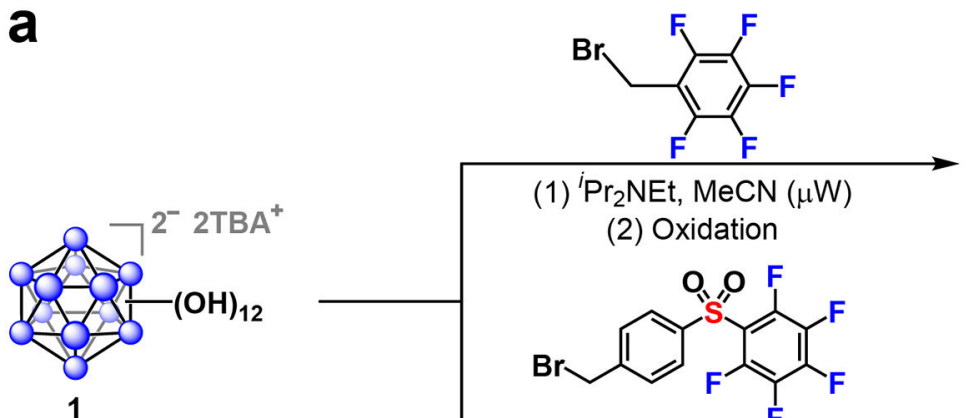

(1) ${ }^{i} \mathrm{Pr}_{2} \mathrm{NEt}, \mathrm{MeCN}(\mu \mathrm{W})$

(2) Oxidation

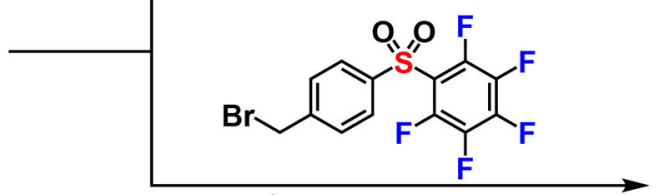

(1) ${ }^{i} \mathrm{Pr}_{2} \mathrm{NEt}, \mathrm{MeCN}(\mu \mathrm{W})$

(2) Ion exchange
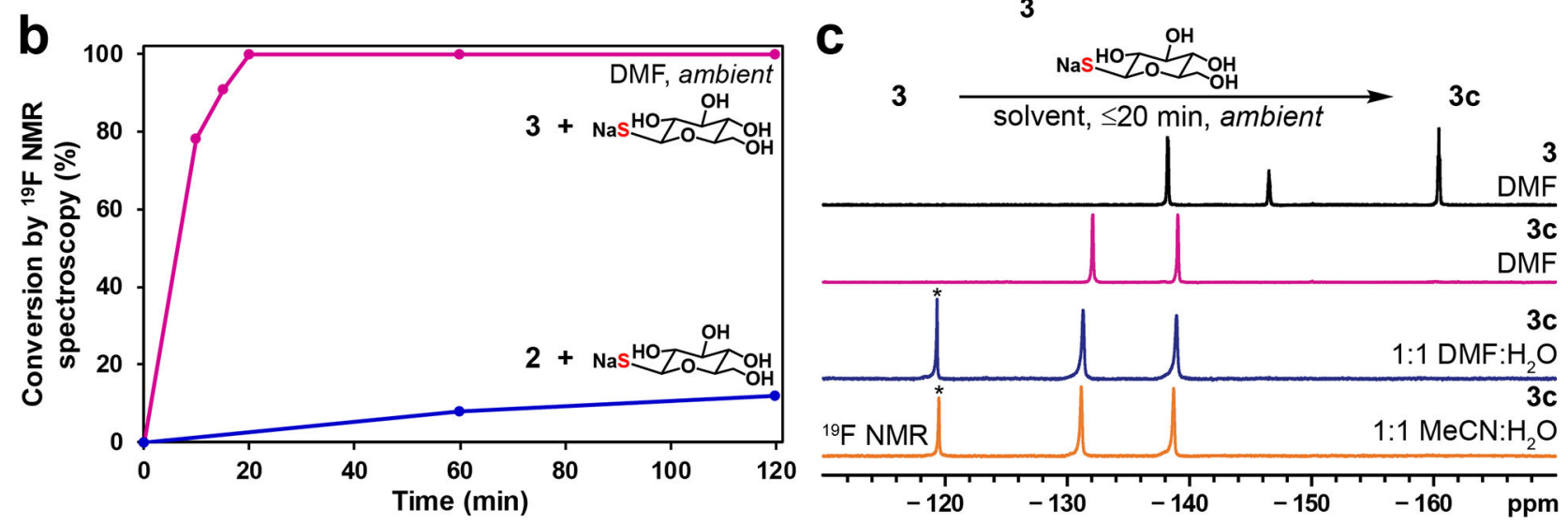

Figure 1.

Synthesis of perfluoroaryl-perfunctionalized clusters and their reactivities toward an unprotected thiolated saccharide. (a) Clusters $\mathbf{2}$ and $\mathbf{3}$ are readily prepared from $\mathbf{1}$ with the assistance of a microwave reactor. (b) Conversion rates of $S_{N} A r$ reactions between $\mathbf{2} / \mathbf{3}$ and 1-thio- $\beta$-D-glucose sodium salt, as monitored by ${ }^{19} \mathrm{~F}$ NMR spectroscopy, reveal the significantly enhanced reactivity of $\mathbf{3}$ over 2 . (c) ${ }^{19} \mathrm{~F}$ NMR spectra of $\mathbf{3}$ in DMF and $\mathbf{3 c}$ after conjugation with 1-thio- $\beta$-D-glucose sodium salt in DMF or mixed aqueous/organic media. *NaF signal. 

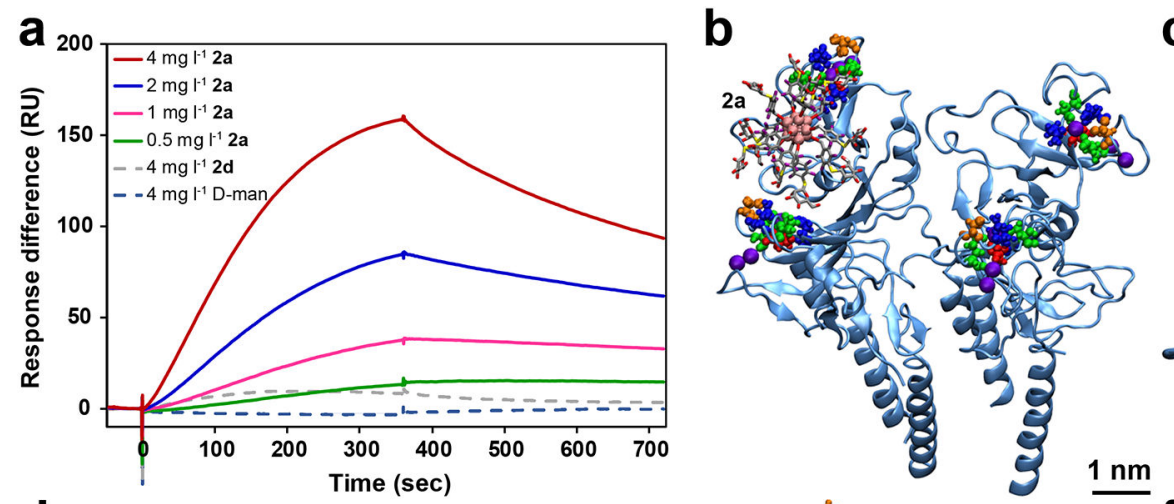

C
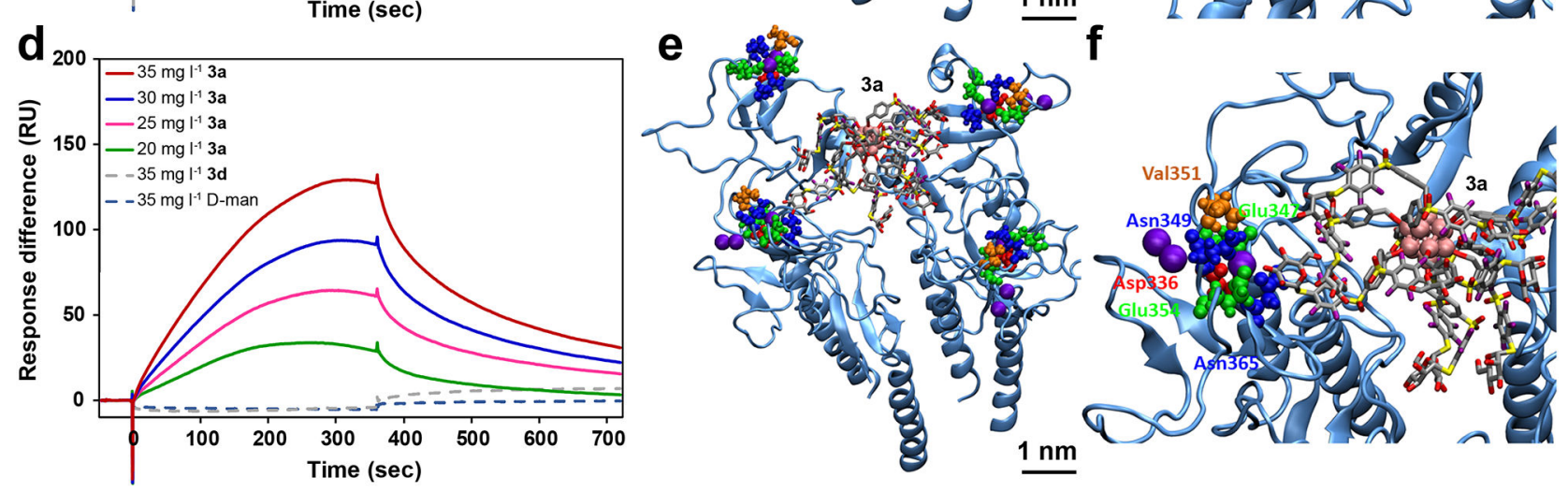

Figure 2.

Multivalent binding interactions between mannose-functionalized nanomolecules and DCSIGN. (a, d) SPR sensorgrams reveal dose-dependent multivalent binding of 2a and 3a to DC-SIGN, respectively, while the controls PEGylated clusters (2d and 3d) and D-mannose exhibit minimal to no binding to DC-SIGN. In all SPR experiments, the flow rate is $5 \mu \mathrm{L} /$ min, and the analytes are injected for 6 minutes, followed by buffer flow. (b, e) Snapshots after 40 ns of MD simulations of the binding interactions between 2a/3a and DC-SIGN. (c, f) Zoomed-in snapshots reveal each nanomolecule binding to the carbohydrate recognition sites of DC-SIGN. See the Supporting Information for the MD simulation movies. 

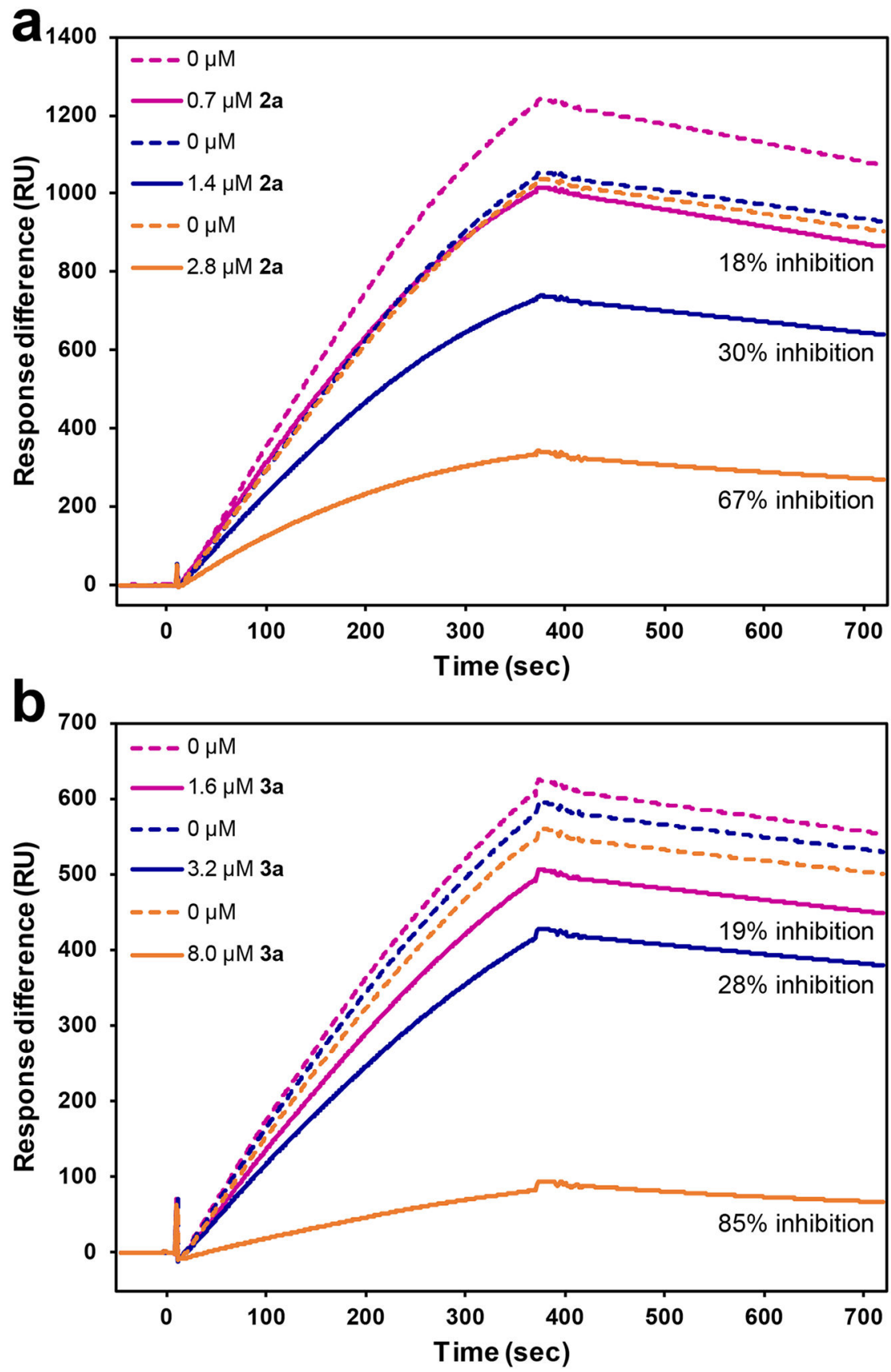

Figure 3.

Mannose-functionalized clusters are capable of inhibiting protein-protein interactions. $(a, b)$ SPR-based competitive binding studies suggest that $\mathbf{2 a}$ and $\mathbf{3 a}$ effectively compete against immobilized gp120 to bind free DC-SIGN, which leads to reduced binding responses. 
a

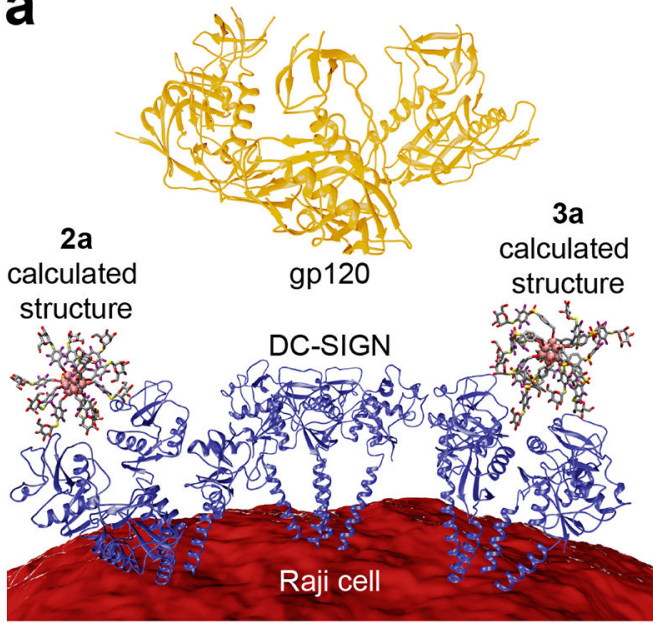

C

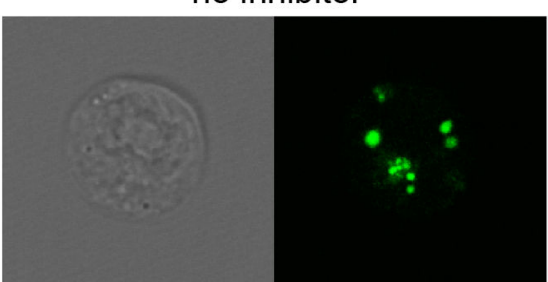

no DC-SIGN

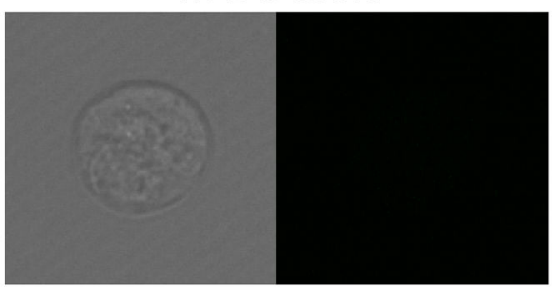

25 uM D-mannose

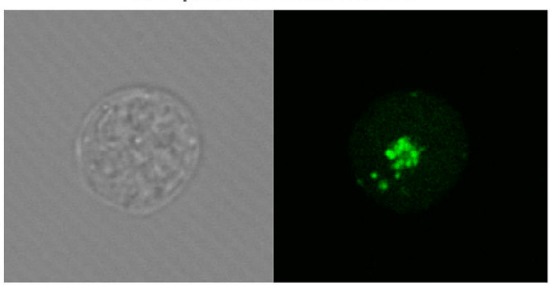

b

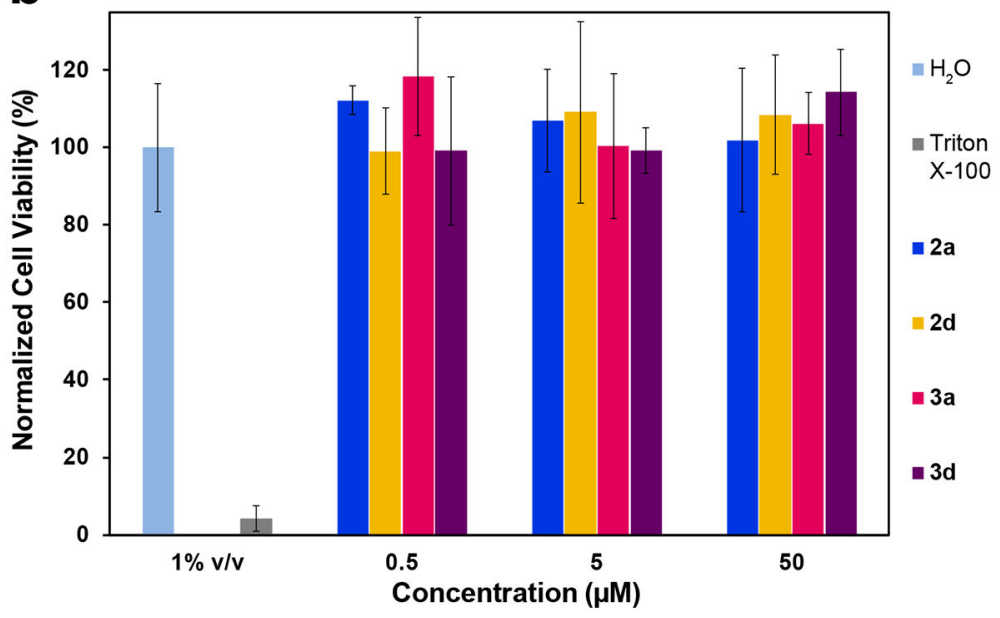

$10 \mu \mathrm{M} 2 \mathrm{a}$

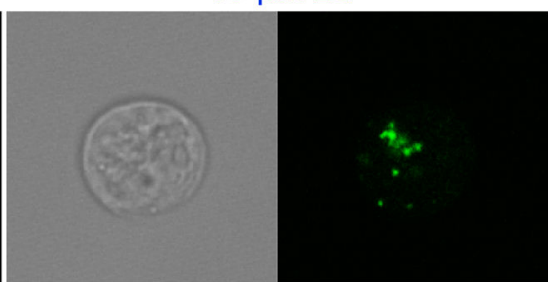

$25 \mu \mathrm{M} 2 \mathrm{a}$

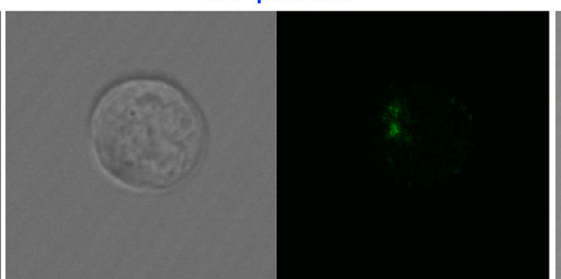

25 uM 2d

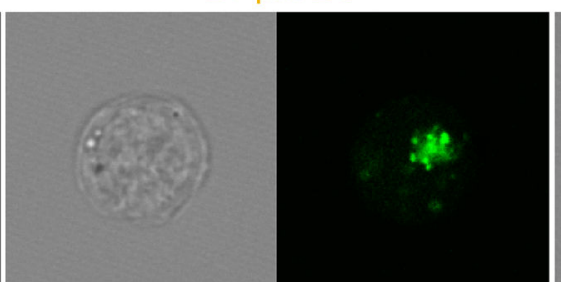

$10 \mu \mathrm{M} 3 \mathrm{a}$

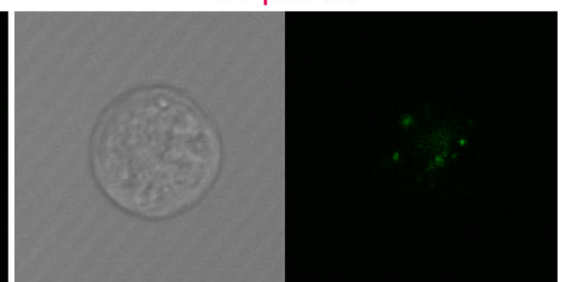

$25 \mu \mathrm{M} 3 \mathrm{a}$

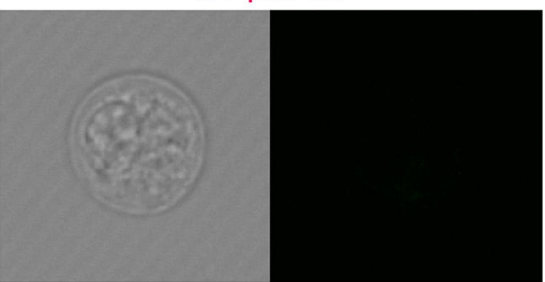

$25 \mu \mathrm{M} 3 \mathrm{~d}$

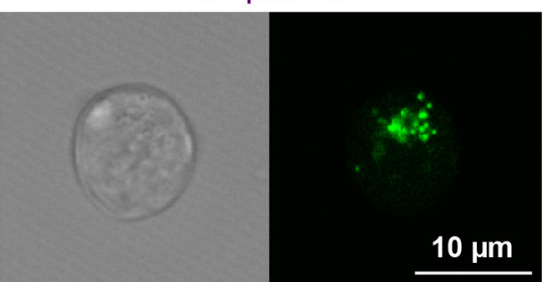

Figure 4.

Biocompatible mannose-coated cluster nanomolecules can serve as multivalent inhibitors to prevent the DC-SIGN-mediated cell uptake of gp120. (a) Glycosylated clusters can potentially inhibit the uptake of viral glycoproteins such as gp120 by blocking cell-surface DC-SIGN. Figure is not drawn to scale. (b) Mannose-coated and PEGylated clusters exhibit no apparent toxicity toward Raji DC-SIGN+ cells at least up to $50 \mu \mathrm{M}$, as assessed by an MTS assay. (c) DC-SIGN-dependent cell uptake of gp120-FITC is inhibited by mannosecoated clusters (2a and 3a), as indicated by confocal microscopy analysis. However, the 
controls PEGylated clusters (2d and 3d) and D-mannose do not affect the uptake of gp120FITC. 
Table 1.

Glycosylation and PEGylation of Clusters 2 and 3

\begin{tabular}{|c|c|c|c|c|c|c|}
\hline Entry & Compound & $\mathbf{L}$ & $\mathbf{R}$ & Time (h) & In situ yield ${ }^{a}(\%)$ & Isolated yield $^{b}(\%)$ \\
\hline 1 & $2 \mathbf{a}$ & none & $\begin{array}{l}\text { "हुn } \\
\text { mannose }\end{array}$ & 48 & $\geqslant 9$ & 80 \\
\hline 2 & $2 b$ & none & galactose & 48 & $\geq 99$ & 84 \\
\hline 3 & $2 c^{*}$ & none & $\underset{\text { glucose }}{\mathrm{HO}} \underset{\text { us }}{\mathrm{OH}}$ & 24 & $\geqslant 99$ & 65 \\
\hline 4 & $2 d^{*}$ & none & x cot ot & 24 & $\geqslant 99$ & 76 \\
\hline 5 & $3 \mathbf{a}$ & & 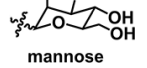 & 0.3 & $\geq 9$ & 83 \\
\hline 6 & $3 \mathbf{b}$ & & & 0.3 & $\geq 99$ & 67 \\
\hline 7 & $3 c$ & & 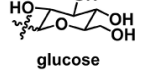 & 0.3 & $\geq 9$ & 77 \\
\hline 8 & 3d & & 3r ot $0 t_{6}$ & 1.5 & $\geq 9$ & 84 \\
\hline
\end{tabular}

${ }^{a}$ Yield determined by ${ }^{19}$ F NMR spectroscopy;

$b_{\text {Isolated yield after purification; }}$

Previously reported compounds. r.t., room temperature. 